\title{
Ashby Receives Von Hippel Award
}

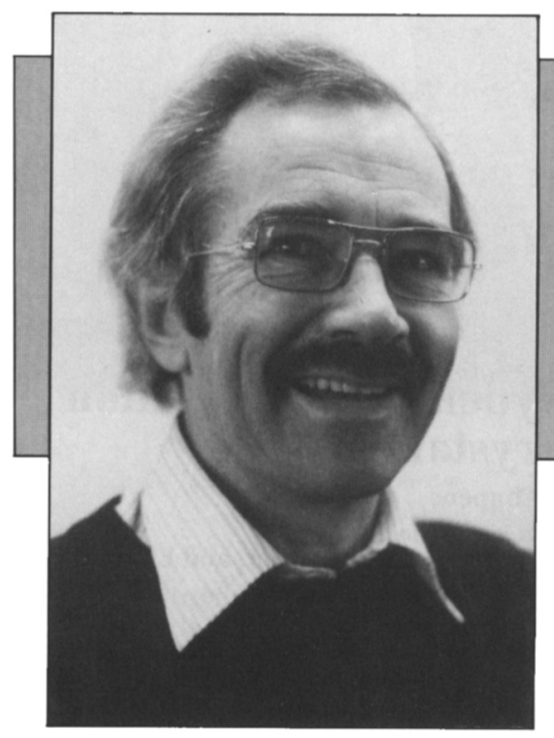

The Von Hippel Award, the Materials Research Society's highest honor, this year goes to Michael F. Ashby for his success in unifying a broad range of materials phenomena and properties and making them more readily accessible to engineers, scientists, and students.

The award honors Ashby's accomplishments for their depth, diversity, creativity, and clarity of thought. Ashby is recognized for achievements which integrate basic research, materials application, and education. He has made seminal contributions to subjects as diverse as dispersion hardening, grain boundary sliding, creep, fracture, sintering, cellular materials, ice mechanics, and wear. His work combines cleverly conceived experiments-often elegant in their simplicity-with insightful theoretical modeling.

Ashby has become the leader in the

\section{"The Von Hippel Award is presented to Michael F. Ashby for his outstanding success in integrating basic materials research and applications, unifying a broad range of complex materials phenomena relating to the mechanical behavior of materials."}

process of rationalization of complex phenomena, by developing maps or diagrammatic representations of a wide range of processes-from deformation and fracture to hot isostatic pressing, welding, wear processes, and mechanics of cellular solids. His research has been characterized by clarity of approach and a broad appreciation of existing scientific literature. He has a penetrating vision which pinpoints key parameters and physical mechanisms.

Ashby's unifying approach has made whole subject areas (deformation, fracture, wear, etc.) accessible to engineers in a new and useful way. For example, Ashby took inelastic deformation mechanisms studied over many years by many researchers and characterized them, using relatively simple relations between the most important variables. These relations were calibrated by existing experimental data and presented as maps, giving, for example, contours of constant strain-rate on a graph of stress versus temperature. His approach makes explicit the importance of understanding underlying mechanisms and emphasizes the danger of trying to extrapolate data from one mechanism regime to another.

More recently, he has coupled his work with an extensive computer data base of material properties, to develop a new approach to materials selection in engineering design. For a given design problem, indices of merit are identified and expressed in terms of material properties. Then the maps are used in conjunction with the data base to expose other possible materials that may meet the design criteria.

Ashby holds a Royal Society Research Professorship in the Engineering Department of the University of Cambridge. He has been a member of the Royal Society since 1979 and was recently elected as a foreign member of the U.S. National Academy of Engineering. Ashby is the recipient of many prestigious awards offered by the materials community. In addition, he has been editor of Acta Metallurgica since 1974. Ashby received his $\mathrm{BA}, \mathrm{MA}$ and $\mathrm{PhD}$ degrees from the University of Cambridge.

The Von Hippel Award is given annually to an individual in recognition of outstanding contributions to interdisciplinary research on materials. The 1992 award will be presented to Ashby on Thursday, December 3, at 6:00 p.m. in Salon E, Boston Marriott Hotel. Immediately after the award presentation, Ashby will give a lecture titled "Materials in Mechanical Design." A wine and cheese reception will follow.

\section{VON HIPPEL AWARD LECTURE}

\author{
Michael F. Ashby, University of Cambridge \\ "Materials in Mechanical Design" \\ *** \\ Thursday, December 3, 1992 \\ 6:00 p.m. • Salon E • Boston Marriott Hotel \\ Reception Following
}

